\title{
Exercise Training and Dietary Glycemic Load May Have Synergistic Effects on Insulin Resistance in Older Obese Adults
}

\author{
John P. Kirwan ${ }^{\text {a-d }}$ Hope Barkoukis ${ }^{d}$ Latina M. Brooks ${ }^{a, b}$ \\ Christine M. Marchetti ${ }^{e}$ Bradley P. Stetzer ${ }^{e}$ Frank Gonzalez ${ }^{f}$ \\ Departments of a Gastroenterology and Hepatology, and ${ }^{\mathrm{b}}$ Pathobiology, Lerner Research Institute, \\ Cleveland Clinic, Departments of ' Physiology and d Nutrition, Case Western Reserve University School of Medicine, \\ and ${ }^{\mathrm{e}}$ Department of Reproductive Biology, Case Western Reserve University School of Medicine and MetroHealth \\ Medical Center, Cleveland, Ohio, and ${ }^{\mathrm{f}}$ Department of Obstetrics and Gynecology, Mayo Clinic, Rochester, Minn., USA
}

\section{Key Words}

Diabetes $\cdot$ Obesity $\cdot$ Aging $\cdot$ Insulin sensitivity $\cdot$ Physical activity $\cdot$ Glycemic index

\begin{abstract}
Background/Aims: The aim of this study was to assess the combined effects of exercise and dietary glycemic load on insulin resistance in older obese adults. Methods: Eleven men and women (62 \pm 2 years; $97.6 \pm 4.8 \mathrm{~kg}$; body mass index $33.2 \pm 2.0$ ) participated in a 12-week supervised exercise program, 5 days/week, for about $1 \mathrm{~h} /$ day, at $80-85 \%$ of maximum heart rate. Dietary glycemic load was calculated from dietary intake records. Insulin resistance was determined using the euglycemic (5.0 mM) hyperinsulinemic (40 $\mathrm{mU} / \mathrm{m}^{2} / \mathrm{min}$ ) clamp. Results: The intervention improved insulin sensitivity $(2.37 \pm 0.37$ to $3.28 \pm 0.52 \mathrm{mg} / \mathrm{kg} / \mathrm{min}, \mathrm{p}<$ $0.004)$, increased $\mathrm{VO}_{2 \max }(\mathrm{p}<0.009)$, and decreased body weight $(p<0.009)$. Despite similar caloric intakes $(1,816 \pm$ 128 vs. $1,610 \pm 100 \mathrm{kcal} /$ day), dietary glycemic load trended towards a decrease during the study (140 $\pm 10 \mathrm{~g}$ before, vs. $115 \pm 8 \mathrm{~g}$ during, $\mathrm{p}<0.04)$. The change in insulin sensitivity correlated with the change in glycemic load $(r=0.84, p<$ 0.009). Four subjects reduced their glycemic load by $61 \pm$
\end{abstract}

$8 \%$, and had significantly greater increases in insulin sensitivity (78 \pm 11 vs. $23 \pm 8 \%, p<0.003)$, and decreases in body weight $(p<0.004)$ and plasma triglycerides $(p<0.04)$ compared to the rest of the group. Conclusion: The data suggest that combining a low-glycemic diet with exercise may provide an alternative and more effective treatment for insulin resistance in older obese adults.

Copyright $\odot 2009$ S. Karger AG, Basel

\section{Introduction}

Diabetes is a source of considerable health burden for our elderly population. Statistics from the United States indicate that individuals over the age of 65 currently account for approximately $40 \%$ of those with diagnosed diabetes, and the prevalence of diabetes is known to increase with advancing age [1]. Identifying effective treatment and prevention strategies is essential to address this public health burden. Exercise and dietary modifications have been broadly recommended as first-line interventions in the treatment of diabetes and insulin resistance, and the success of randomized controlled trials such as the Diabetes Prevention Program underscores the effec-

\section{KARGER}

Fax +41613061234 E-Mail karger@karger.ch www.karger.com
(C) 2009 S. Karger AG, Basel

0250-6807/09/0554-0326\$26.00/0

Accessible online at:

www.karger.com/anm
John P. Kirwan, PhD

Department of Gastroenterology and Hepatology

Cleveland Clinic, Lerner Research Institute

9500 Euclid Ave/NE4-209, Cleveland, OH 44195 (USA)

Tel. +1 216444 3412, Fax +1 216636 0104, E-Mail kirwanj@ccf.org 
tiveness of lifestyle changes compared to pharmacotherapy in reducing the risk of diabetes, particularly among those over the age of 60 years [2].

Diet alone has been shown to improve insulin sensitivity and the risk of type 2 diabetes; however, the composition of the diet and the precise role of carbohydrate quantity and quality remain unresolved. The glycemic index provides a means to quantify carbohydrate quality. It classifies carbohydrate foods according to the incremental plasma glucose response observed following consumption of a specific carbohydrate food relative to the glucose response observed following ingestion of an equivalent amount of a standard, either glucose or white bread [3]. The glycemic load incorporates both carbohydrate quantity and quality since it reflects the product of the glycemic index and total dietary carbohydrates. The concept that the glycemic load influences the risk of glucose intolerance, type 2 diabetes, and insulin resistance is increasingly recognized [4]. However, studies examining the effects of low- and high-glycemic diets on insulin sensitivity in humans have yielded equivocal results [57]. Kiens and Richter [7] conducted a 30-day randomized crossover high- and low-glycemic diet study on young healthy men and reported that insulin sensitivity was similar for both diets. Jarvi et al. [6] found an increase in insulin sensitivity in lean type 2 diabetics after 3 weeks on high- and low-glycemic diets. Frost et al. [5] performed a 3-week randomized trial using high- and low-glycemic diets in young women with a family history of coronary heart disease; insulin sensitivity was increased on the low-glycemic diet and decreased on the high-glycemic diet. A recent study by Philippou et al. [8] provided energy-restricted high- and low-glycemic diets to overweight/obese volunteers for 12 weeks and found that weight loss and glucose metabolism were more favorably improved following the low-glycemic diet. To date, there are no comprehensive studies on the effects of more prolonged high- or low-glycemic diets on insulin resistance in older obese adults.

On the other hand, there is a substantial literature showing a reversal of insulin resistance after exercise training [9-14]. Additional studies using a short-term exercise training model have shown that exercise-induced improvements in insulin sensitivity and responsiveness can be achieved independent of weight loss, and most likely manifest through enhanced insulin signaling and recruitment of the glucose transporter, GLUT-4 [15-18]. However, there are responders and nonresponders to these training programs, giving rise to heterogeneity in insulin responsiveness to exercise that is poorly under- stood. One likely source of the variation is an interaction between exercise training and diet composition. Studies that have combined acute exercise and low- or moderateglycemic meals show enhanced exercise performance via a preference for lipid utilization and more efficient hepatic glucose regulation during exercise [19-23]. This suggests that a low-glycemic diet has the potential to complement exercise during long-term lifestyle interventions. In the context of the present report, there are no data on the possible interaction between these types of diets and exercise training. Herein we examine the effects of diet composition on insulin sensitivity in older obese adults who participated in a 12-week supervised exercisetraining program. The working hypothesis was that the glycemic content of the diet would influence the magnitude of the exercise-induced improvement in insulin sensitivity.

\section{Subjects and Methods}

\section{Subjects}

Eleven men and women ( 6 females, and 5 males) aged 60-75 years volunteered to participate in the study. All subjects were obese, with a mean body mass index (BMI) of 33.0. Subjects were excluded if they had any acute or chronic illnesses or used any medications that would interfere with exercising, weight loss, or carbohydrate or lipid metabolism. Women who had taken hormone replacement therapy in the 12 months preceding the study were also excluded. None of the subjects had been involved in any endurance exercise program for at least 12 months before the time of testing. Subjects in this study were part of a larger research trial examining the effects of exercise and diet on insulin resistance in older obese adults. The protocol was approved by the Institutional Review Board at MetroHealth Medical Center and all subjects provided written informed consent in accordance with guidelines for the protection of human subjects.

\section{Study Design}

The study was an intervention trial that consisted of 12 weeks of supervised exercise combined with a monitored eucaloric diet. All medical screening, physiological and metabolic tests were performed prior to the exercise intervention. Insulin sensitivity, exercise fitness and body composition measures were obtained at baseline and all testing was repeated after the 12 -week program.

\section{Exercise}

The subjects participated in a treadmill test to determine their maximal oxygen consumption $\left(\mathrm{VO}_{2 \max }\right)$ using a constant-speed (2-4 mph), incremental-grade (1.5-2.5\% every $2 \mathrm{~min}$ ) protocol. Measurements of $\mathrm{VO}_{2 \max }$ and maximal heart rate $\left(\mathrm{HR}_{\max }\right)$ were used to determine the appropriate exercise-training intensity. Exercise training consisted of walking on a treadmill and stationary cycling on a cycle ergometer. Subjects trained once a day, 5 days/ week, 50-60 $\mathrm{min} / \mathrm{session}$, for 12 weeks. Initially subjects exercised at $55-60 \%$ of $\mathrm{HR}_{\max }$ and were gradually increased over a 2- to 3- 
week period to $80-85 \%$ of $\mathrm{HR}_{\max }$. The test was repeated at 4 -week intervals to adjust training intensity and to assure compliance with the prescribed training program. All of the exercise sessions were supervised by an exercise physiologist and were performed on site in the General Clinical Research Center.

\section{Diet}

Subjects were instructed on how to complete dietary records and were told to maintain their normal dietary intake throughout the study. All subjects completed 3-day food records during the baseline phase of the study, and this was repeated during weeks 3 , 6,9 , and 12 of the program. Subjects met with a dietitian before and at 4-week intervals throughout the study. Dietary intake was assessed using Nutritionist Pro ${ }^{\mathrm{TM}}$ software (Axxya, Stafford, Tex., USA). Glycemic load was calculated by multiplying the glycemic index for the carbohydrate food by the amount of carbohydrate that was eaten. In order to assess the role of glycemic load, the average glycemic-load data from weeks 9 and 12 were combined and compared to data from the glycemic load reported for the preintervention baseline diets.

\section{Euglycemic-Hyperinsulinemic Clamps}

Insulin sensitivity was measured using the euglycemic-hyperinsulinemic clamp procedure as previously described [24, 25]. Clamps were performed after a 10-12-hour overnight fast, and for postintervention testing, approximately $18 \mathrm{~h}$ after the last exercise bout. A polyethylene catheter was inserted into an antecubital vein for infusion of insulin $\left(40 \mathrm{mU} / \mathrm{m}^{2} / \mathrm{min}\right)$ and glucose $(5.0 \mathrm{mM}$ glucose). A second catheter was inserted retrograde into a dorsal hand vein, which was warmed in a heated box for sampling of arterialized venous blood. Blood glucose was measured immediately using the glucose oxidase method (YSI 2300 STAT Plus, Yellow Springs, Ohio, USA). Blood samples for insulin measurements were centrifuged at $4^{\circ} \mathrm{C}$, and the plasma was stored at $-80^{\circ} \mathrm{C}$ for subsequent analysis by a double-antibody radioimmunoassay (RIA, Linco Research, St. Charles, Mo., USA). Blood lipids were analyzed by enzymatic analysis on an automated platform (Roche Modular Diagnostics, Indianapolis, Ind., USA). Plasma tumor necrosis factor- $\alpha$ concentrations were measured by ELISA (Quantikine HS; R\&D Systems, Minneapolis, Minn., USA). Dietary intake and physical activity were controlled for 3 days prior to the euglycemic-hyperinsulinemic clamp procedure.

\section{Body Composition}

Body composition was determined at baseline and again after the 12-week exercise program. Height without shoes was measured to the nearest $1.0 \mathrm{~cm}$. Body weight was measured to the nearest $0.1 \mathrm{~kg}$. Body density was determined by hydrostatic weighing and percent body fat was estimated using the Siri equation as previously described [11].

\section{Statistics}

Data are presented as means \pm SE. Differences between dependent variables were examined with a one-way ANOVA, ANCOVA, or paired Student $t$ test. The relationship between insulin sensitivity measured during the clamp and changes in glycemic load was based on univariate and multivariate correlation analysis. The data were analyzed using the Statview II statistical package (Abacus Concepts, Berkeley, Calif., USA). The $\alpha$-level for statistical significance was set at 0.05 .
Table 1. Participant characteristics

\begin{tabular}{lcc}
\hline Characteristic & $\begin{array}{l}\text { Before the } \\
\text { intervention }\end{array}$ & $\begin{array}{l}\text { After the } \\
\text { intervention }\end{array}$ \\
\hline Age, years & $62 \pm 2$ & \\
Body weight, kg & $97.6 \pm 4.8$ & $93.7 \pm 4.6^{*}$ \\
BMI, $\mathrm{kg} / \mathrm{m}^{2}$ & $33.2 \pm 2.0$ & $32 \pm 2.0^{*}$ \\
Body fat, \% & $39.4 \pm 1.6$ & $35.9 \pm 2.2$ \\
$\mathrm{VO}_{2 \mathrm{max}}, \mathrm{ml} / \mathrm{kg} \mathrm{FFM} / \mathrm{min}$ & $37.0 \pm 1.7$ & $41.0 \pm 2.3^{*}$ \\
$\mathrm{Glucose}_{\mathrm{m}} / \mathrm{dl}$ & $105 \pm 4$ & $102 \pm 3$ \\
Insulin, $\mu \mathrm{U} / \mathrm{ml}$ & $21.9 \pm 3.5$ & $16.0 \pm 2.0^{*}$ \\
Triglycerides, $\mathrm{mg} / \mathrm{dl}$ & $170.1 \pm 28.3$ & $148.1 \pm 22.8$ \\
Cholesterol, $\mathrm{mg} / \mathrm{dl}$ & $193.4 \pm 10.4$ & $177.4 \pm 9.3^{*}$ \\
TNF- $\alpha, \mathrm{pg} / \mathrm{ml}$ & $3.0 \pm 0.6$ & $2.6 \pm 0.5$ \\
\hline
\end{tabular}

Data are means \pm SE. $\mathrm{n}=11 ; 5$ men and 6 women. ${ }^{*} \mathrm{p}<0.05$, significant difference between pre- and postintervention measures. FFM = Fat-free body mass; TNF- $\alpha=$ Tumor necrosis factor- $\alpha$.

\section{Results}

\section{Subjects}

Despite being obese (BMI $\left.33.2 \pm 2.0 \mathrm{~kg} / \mathrm{m}^{2}\right)$, the subjects were relatively healthy and all subjects were able to successfully complete the exercise-training program. Demographic data are presented in table 1. Subjects lost weight ( $p<0.009)$, decreased their BMI $(p<0.009)$, and reduced their body fat $(\mathrm{p}<0.01)$.

\section{Exercise Responses to the Training Intervention}

Physical fitness, based on $\mathrm{VO}_{2 \max }$ testing indicated a significant improvement in aerobic capacity after completion of the intervention (table 1). Compliance with the program, which was supervised, was excellent; subjects completed an average of $4.7 \pm 0.2$ sessions per week. Average heart rate during the training was $123 \pm 2 \mathrm{bpm}$, which corresponds to $79 \pm 1 \%$ of $\mathrm{HR}_{\max }$.

\section{Effects of the Exercise Intervention on Insulin}

\section{Resistance and Blood Measures}

Insulin resistance assessed from the glucose disposal rate during euglycemic-hyperinsulinemic clamps revealed a marked improvement after the intervention $(2.37 \pm$ 0.37 to $3.28 \pm 0.52 \mathrm{mg} / \mathrm{kg} / \mathrm{min}, \mathrm{p}<0.004)$ for pre- and postintervention measurements, respectively (fig. 1a). Fasting insulin levels were also improved after the intervention $(21.9 \pm 3.5$ vs. $16.0 \pm 2.0 \mu \mathrm{U} / \mathrm{ml}$, respectively, $\mathrm{p}<0.01$, table 1). Fasting plasma glucose and triglycerides were not significantly affected while total cholesterol was 

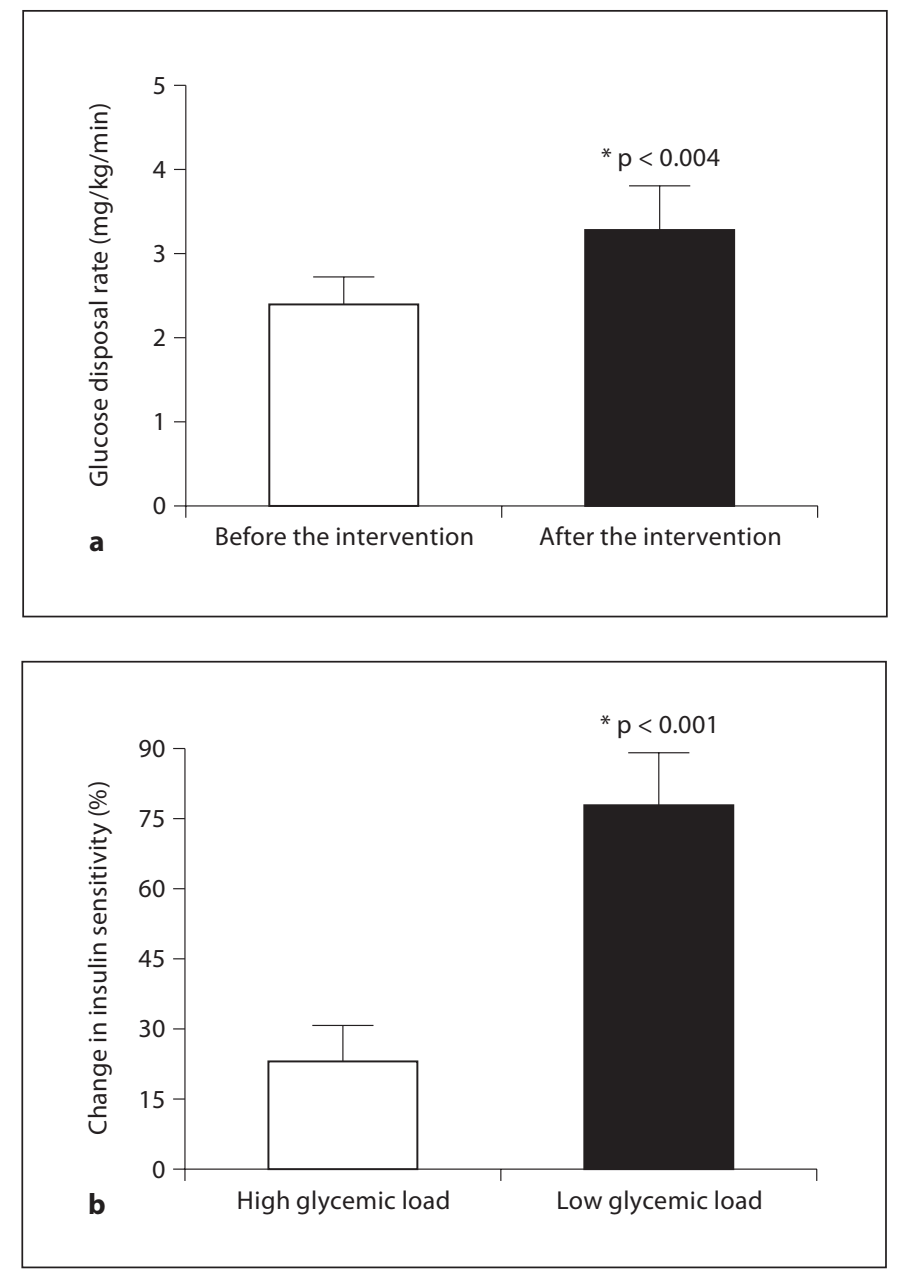

Fig. 1. Effects of exercise training and diet on insulin sensitivity. Eleven older, obese, and previously sedentary adults participated in a 12-week aerobic exercise-training intervention during which they were required to maintain a eucaloric diet (about $1,700 \mathrm{kcal} /$ day). Insulin-mediated glucose disposal was significantly improved after the intervention $(\mathrm{p}<0.004 ; \mathbf{a})$. b All subjects maintained a eucaloric diet, but 4 of the 11 independently changed their food selection such that they were eating a low-glycemic load diet. These subjects increased their insulin sensitivity by $78 \pm$ $11 \%$ compared to $23 \pm 8 \%$ for the rest of the group ( $p<0.003$ ). Data represent means $\pm \mathrm{SE}$.

improved (table 1). Likewise, plasma tumor necrosis factor- $\alpha$ was unchanged by exercise training (table 1). Examination of the glucose clamp data revealed a notable heterogeneity in the magnitude of change in insulin sensitivity among subjects. Clearly, 4 of the 11 subjects demonstrated a more marked improvement in insulin sensitivity (78 $\pm 11 \%$, fig. $1 b)$ compared to the rest of the group $(1.53 \pm 0.42$ vs. $0.56 \pm 0.23 \mathrm{mg} / \mathrm{kg} / \mathrm{min}, \mathrm{p}<0.05)$.
Table 2. Diet composition

\begin{tabular}{lcc}
\hline & $\begin{array}{l}\text { Before the } \\
\text { intervention }\end{array}$ & $\begin{array}{l}\text { After the } \\
\text { intervention }\end{array}$ \\
\hline Energy intake, kcal/day & $1,816 \pm 128$ & $1,610 \pm 100$ \\
Carbohydrate, g & $225.0 \pm 12.9$ & $200.5 \pm 13.3$ \\
Fat, g & $72.1 \pm 8.3$ & $60.1 \pm 6.3$ \\
Protein, g & $79.0 \pm 7.2$ & $77.3 \pm 7.9$ \\
Fiber, g & $18.6 \pm 1.7$ & $19.1 \pm 1.5$ \\
Glycemic load, g & $140.1 \pm 10.1$ & $115.1 \pm 7.8^{*}$ \\
\hline
\end{tabular}

Data are means \pm SE. $\mathrm{n}=11,5$ men and 6 women. ${ }^{*} \mathrm{p}<0.05$, significant decrease comparing pre- and postintervention measures.

These subjects also demonstrated greater decreases in body weight $(7.8 \pm 1.5$ vs. $1.6 \pm 0.8 \mathrm{~kg}, \mathrm{p}<0.004)$ and plasma triglycerides $(74.0 \pm 29.2$ vs. $7.7 \pm 11.4 \mathrm{mg} / \mathrm{dl}$, $\mathrm{p}<0.01)$. We then examined the change in insulin sensitivity between these subgroups using body weight and plasma triglycerides as covariates. The change in insulin sensitivity between the subgroups continued to be significant ( $\mathrm{p}<0.01$ using body weight, and $\mathrm{p}<0.009$ using triglycerides). Importantly, subjects in both subgroups were quite homogeneous in terms of phenotype, blood pressure, exercise capacity, fasting blood glucose and lipids, and baseline insulin sensitivity. The observations for the subset of high responders prompted us to search for possible explanations for their greater improvement in insulin sensitivity. One of the first factors considered was dietary intake.

\section{Dietary Intake and Glycemic Load}

Subjects had been counseled at 4 -week intervals by a dietitian and were requested to maintain their normal macronutrient and caloric intake throughout the study. Assessment of dietary intake based on 3-day diet records revealed an average caloric intake of $1,816 \pm 128 \mathrm{kcal} /$ day before the intervention versus $1,610 \pm 100 \mathrm{kcal} /$ day after the intervention, with $50 \%$ of macronutrients coming from carbohydrate, 34\% from fat, and 19\% from protein (table 2). Postintervention macronutrient and calorie intakes were similar to preintervention intakes, indicating good compliance with this aspect of the study. Preintervention and postintervention sucrose intakes for the combined group were also similar ( $33.3 \pm 7.6$ vs. $32.3 \pm$ $4.8 \mathrm{~g} /$ day, respectively), but while subgroup intakes were not different after the intervention $(35.6 \pm 6.7$ vs. $28.2 \pm$ 


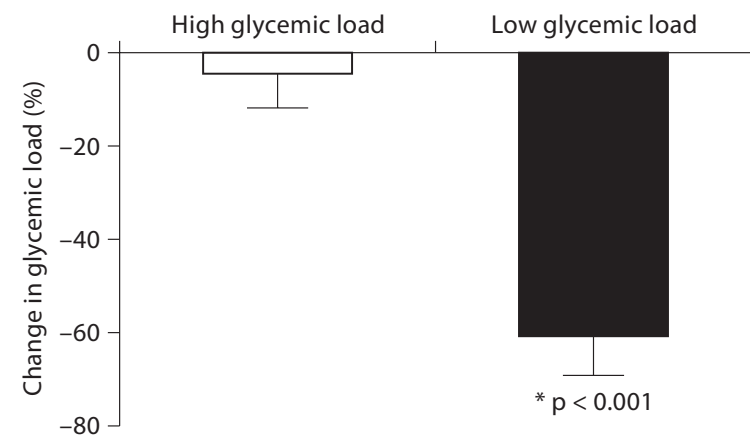

Fig. 2. Changes in glycemic load. Subjects were instructed to maintain a eucaloric diet, but 4 of the 11 independently changed their food selection such that they consumed a low-GL diet without changing their calorie intake. Data show a significant difference in glycemic load between the two subgroups ( $p<0.001)$. Data represent means $\pm \mathrm{SE}$.

$7.2 \mathrm{~g} / \mathrm{day}$, for the high- vs. low-glycemic load groups, respectively), the percent change in intakes tended to be lower in the low-glycemic load group $(p=0.08)$. Based on established glycemic indices for the reported foods, we estimated the dietary glycemic load [26]. Pre- to postintervention records indicated a $25 \pm 10 \%$ reduction in glycemic load, which was marginally significant for the group as a whole $(\mathrm{p}=0.03)$. However, the 4 subjects who had shown the greatest increase in insulin sensitivity contributed most of the reduction. These subjects reduced their glycemic load by $61 \pm 8 \%$, from $165.7 \pm 10.0$ to $104.9 \pm 12.5 \mathrm{~g}$ (fig. 2), without changing their macronutrient percentages or total calorie intakes.

\section{Effects of the Exercise Intervention and Dietary}

Glycemic Load on Insulin Resistance

In univariate analyses, the percent change in insulin sensitivity was strongly associated with the change in glycemic load ( $\mathrm{r}=0.84, \mathrm{p}<0.001$; fig. 3 ) while the association with change in body weight showed a trend towards significance $(r=0.53, p=0.09)$. Using a stepwise regression analysis model that included glycemic load, body weight, calorie intake, fiber intake, triglycerides, total cholesterol, and $\mathrm{VO}_{2 \max }$, the change in glycemic load was found to be a primary predictor of improved insulin sensitivity and explained $>66 \%$ of the variance in the model $(\mathrm{r}=81, \mathrm{p}<0.03)$.

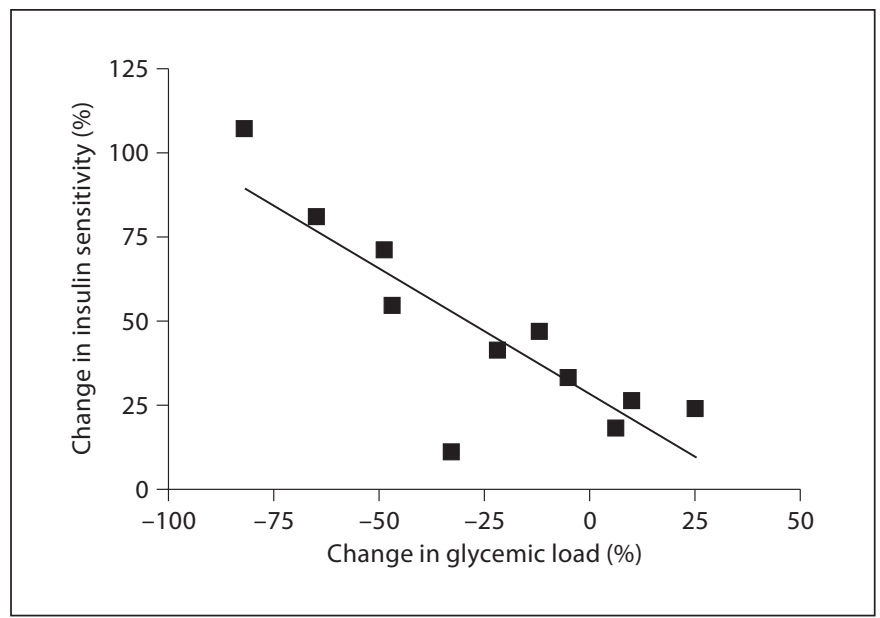

Fig. 3. Relationship between change in glycemic load and change in insulin sensitivity. Data represent the percent change in glycemic load and insulin sensitivity from baseline to the postintervention period for all 11 subjects. There was a significant correlation between the variables such that those consuming a diet with a lower glycemic load achieved a greater improvement in insulin sensitivity $(\mathrm{r}=0.84, \mathrm{p}<0.009)$.

\section{Discussion}

We proposed that exercise training would reduce insulin resistance in older obese adults, and that this response would be modulated by the glycemic content of the diet. After 12 weeks of aerobic exercise, obese men and women demonstrated a $47 \pm 9 \%$ improvement in insulin sensitivity and reduced the glycemic load in their diet by $25 \pm 10 \%$ without any significant change in energy intake. The decrease in insulin resistance correlated with the reduction in glycemic load. Additionally, those who made the greatest change in the glycemic content of their diet (decreased by $61 \pm 8 \%$ ) experienced significantly greater improvements in insulin sensitivity $(78 \pm$ $11 \%)$. These data suggest that insulin resistance can be reversed with a relatively short-term aerobic exercisetraining program, but that the improvement in insulin sensitivity may be further enhanced by consuming a lowglycemic diet. The data point to a potential synergy between exercise and a low-glycemic diet as an integral treatment modality for insulin resistance and type 2 diabetes.

The prevalence of obesity, insulin resistance and type 2 diabetes has dramatically increased in older adults in the past 3 decades. Furthermore, diabetes is associated with excess morbidity and mortality across all age groups, but this is seen most frequently in the elderly [27]. The 
Diabetes Prevention Program provides some of the strongest data to support the role of exercise and diet in reducing the risk of developing type 2 diabetes [2]. A systematic lifestyle intervention was more than twice as effective as metformin in attenuating risk in those over the age of 60 years. The effect of exercise training alone on insulin sensitivity is well established in young obese and type 2 diabetic populations $[9,10,12]$ although this observation is not universal [28]. Older subjects also show positive adaptations to exercise training, but these observations were not made in all studies [11, 13, 14, 29, 30]. Indeed, it was recently shown that nonobese older women only improved insulin sensitivity after high-intensity (about $80 \%$ $\mathrm{VO}_{2 \text { peak }}$ ) exercise training [29]. In the present study, exercise intensity was set at a more modest level (about 70\% $\mathrm{VO}_{2 \max }$ ) yet these older obese individuals showed positive adaptations demonstrating significant improvements in insulin sensitivity, increases in fitness, and decreases in body weight. The magnitude of the improvement in insulin sensitivity for the higher glycemic-load subgroup alone was approximately $28 \%$, which compares favorably to other exercise studies that have demonstrated improved insulin sensitivity in overweight and obese adults [9-14]. However, one of the most novel observations from our current study was the superior response among 4 of the subjects who increased their insulin sensitivity by $78 \%$, i.e. almost 3 times what is normally seen after similar exercise interventions. These 'super-responders' prompted us to probe for potential factors that might contribute to the greater increase in insulin sensitivity. While others have identified differences in gene expression profiles between those who respond and do not respond to exercise [31,32], we elected to examine the possibility that diet composition may have played a role.

While lifestyle interventions are now widely accepted as the first-line treatment for obesity, diabetes, and related metabolic problems, there is no consensus on the most appropriate diet composition for managing these conditions. Low-fat, high-carbohydrate diets have traditionally been the dietary recommendation of choice [33, 34]. However, Hughes et al. [35] have shown that highcarbohydrate diets do not improve insulin sensitivity in older adults. However, this does not take into account that the metabolic response varies substantially between carbohydrates, as evidenced by different glycemic and insulinemic responses [3]. Diets that include carbohydrates with a low-glycemic response result in lower glucose and lipid levels when compared to high-glycemic diets $[8,36$, 37]. While there are no long-term clinical trials examining the effects of high- or low-glycemic diets on insulin resistance or obesity in the elderly, two small clinical trials report greater weight loss utilizing a low-glycemic approach $[8,38]$. Studies conducted by our group observed improvements in insulin and glucose metabolism in insulin-resistant cirrhotic patients after a low-glycemic diet [39]. In addition, two epidemiological studies indicate that eating a high-glycemic diet is a significant independent predictor of diabetes risk $[40,41]$. These data suggest that low-glycemic diets may be more advantageous than high-glycemic diets in reducing obesity and insulin resistance. Data from the present study support these observations. While our subjects were not provided a specific diet, there is evidence that the subjects who selected lower-glycemic foods experienced greater improvements in insulin sensitivity. Importantly, this was achieved without significantly changing energy intake. While the glycemic content of the diet may not be the sole determinant of the markedly improved insulin sensitivity in these individuals, the data strongly suggest that reducing the glycemic load may provide a way to optimize the reversal of insulin resistance in obese subjects.

There are good reasons to think that the combined effect of exercise and reduced glycemic load might synergistically affect insulin resistance. Obesity, lipotoxicity, and low levels of chronic inflammation are among the factors that contribute to insulin resistance. Studies show that low-glycemic diets are highly effective in reducing body weight $[8,38,42]$. Likewise, exercise is effective in lowering body weight, particularly when performed at the level prescribed for the subjects in the current study [11]. Both exercise and low-glycemic diets have been shown separately to be highly effective in reducing circulating lipids, including low-density lipoproteins [38]. Exercise and low-glycemic diets have also been shown to separately reduce inflammation in obese and insulin-resistant adults [43-46]. Further support may be gleaned indirectly from studies that have combined acute exercise and low- or moderate-glycemic meals, resulting in enhanced performance and hepatic glucose regulation [1922]. While these data suggest that the two interventions may be metabolically compatible during exercise, there are no data to show how the two might interact over an extended period of time. Compared to the rest of the study subjects, the subgroup of 'super-responders' in the current study reported a change in food choices that resulted in a shift from a high- to a low-glycemic diet. These subjects experienced substantial improvements in insulin sensitivity that were accompanied by greater weight loss, and greater improvements in circulating lipids, particularly triglycerides. In contrast, plasma tumor necrosis 
factor- $\alpha$ levels were similar for the main group and the subgroup after the intervention. The latter observation suggests that reversal of inflammation does not explain the improved insulin resistance, at least based on the limited evaluation of this outcome, while greater reductions in body weight and lowering of lipids may play a role and contribute to how a low-glycemic diet coupled with exercise can have such a dramatic effect on insulin resistance.

In summary, we have demonstrated that insulin resistance is reduced following 12 weeks of supervised aerobic exercise. These data also show that in a limited subset of subjects consuming a low-glycemic diet during the exercise intervention there is an even greater improvement in insulin sensitivity than when subjects maintain their normal moderate/high-glycemic diet. Such improvements in insulin sensitivity suggest a possible synergism between exercise and a low-glycemic diet that can be used to treat insulin resistance and type 2 diabetes in obese adults more effectively. Larger-scale clinical trials are needed to determine whether a lifestyle intervention that includes exercise and a low-glycemic diet is capable of effectively reducing the morbidity and mortality associated with insulin resistance and diabetes.

\section{Acknowledgments}

The authors would like to thank the research volunteers for their cooperation and compliance with the project, and are greatly appreciative of the dietary support provided by Alicia Thomas, RD in the GCRC Metabolic Kitchen. This project was sponsored by NIH grant RO1 AG12834, General Clinical Research Center grant R00080, and Diabetes Association of Greater Cleveland grant 467R01.

\section{References}

1 Harris MI, Flegal KM, Cowie CC, Eberhardt MS, Goldstein DE, Little RR, Wiedmeyer HM, Byrd-Holt DD: Prevalence of diabetes, impaired fasting glucose, and impaired glucose tolerance in US adults: The Third National Health and Nutrition Examination Survey 1988-1994. Diabetes Care 1998;21: 518-524.

-2 Diabetes Prevention Program Research Group: Reduction in the incidence of type 2 diabetes with lifestyle intervention or metformin. N Engl J Med 2002;346:393-403.

- 3 Jenkins DJA, Thomas DM, Wolever MS, Taylor RH, Barker H, Hashmein Fielden SRD, Baldwin JM, Bowling AC, Newman HC, Jenkins AL, Goff DV: Glycemic index of foods: a physiological basis for carbohydrate exchange. Am J Clin Nutr 1981;34:362-366.

-4 Howlett J, Ashwell M: Glycemic response and health: summary of a workshop. Am J Clin Nutr 2008;87:212S-216S.

-5 Frost G, Leeds A, Trew G, Margara R, Dornhorst A: Insulin sensitivity in women at risk of coronary heart disease and the effect of a low glycemic diet. Metabolism 1998;47: 1245-1251.

-6 Järvi AE, Karlström BE, Granfeldt YE, Björck IE, Asp NG, Vessby BO: Improved glycemic control and lipid profile and normalized fibrinolytic activity on a low-glycemic index diet in type 2 diabetic patients. Diabetes Care 1999;22:10-18.

-7 Kiens B, Richter EA: Types of carbohydrate in an ordinary diet affect insulin action and muscle substrates in humans. Am J Clin Nutr 1996;63:47-53.
-8 Philippou E, McGowan BM, Brynes AE, Dornhorst A, Leeds AR, Frost GS: The effect of a 12-week low glycaemic index diet on heart disease risk factors and $24 \mathrm{~h}$ glycaemic response in healthy middle-aged volunteers at risk of heart disease: a pilot study. Eur J Clin Nutr 2008;62:145-149.

$\checkmark$ Dube JJ, Amati F, Stefanovic-Racic M, Toledo FG, Sauers SE, Goodpaster BH: Exerciseinduced alterations in intramyocellular lipids and insulin resistance: the athlete's paradox revisited. Am J Physiol Endocrinol Metab 2008;294:E882-E888.

$\longrightarrow 10$ Bruce CR, Kriketos AD, Cooney GJ, Hawley JA: Disassociation of muscle triglyceride content and insulin sensitivity after exercise training in patients with type 2 diabetes. $\mathrm{Di}$ abetologia 2004;47:23-30.

11 O'Leary VB, Marchetti CM, Krishnan RK Stetzer BP, Gonzalez F, Kirwan JP: Exerciseinduced reversal of insulin resistance in obese elderly is associated with reduced visceral fat. J Appl Physiol 2006;100:15841589.

12 Houmard JA, Tanner CJ, Slentz CA, Duscha BD, McCartney JS, Kraus WE: Effect of the volume and intensity of exercise training on insulin sensitivity. J Appl Physiol 2004;96: 101-106.

-13 Ferrara CM, Goldberg AP, Ortmeyer HK Ryan AS: Effects of aerobic and resistive exercise training on glucose disposal and skeletal muscle metabolism in older men. J Gerontol A Biol Sci Med Sci 2006;61:480 487.
14 Coker RH, Hays NP, Williams RH, Brown AD, Freeling SA, Kortebein PM, Sullivan DH, Starling RD, Evans WJ: Exercise-induced changes in insulin action and glycogen metabolism in elderly adults. Med Sci Sports Exerc 2006;38:433-438.

15 Houmard J, Shaw C, Hickey M, Tanner C: Effect of short-term exercise training on insulin-stimulated PI 3-kinase activity in human skeletal muscle. Am J Physiol 1999;277: E1055-E1060.

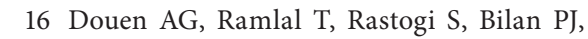
Cartee GD, Vranic M, Holloszy JO, Klip A: Exercise induces recruitment of the 'insulinresponsive glucose transporter'. Evidence for distinct intracellular insulin- and exerciserecruitable transporter pools in skeletal muscle. J Biol Chem 1990;265:13427-13430.

17 Kirwan JP, Solomon TP, Wojta DM, Staten MA, Holloszy JO: Effects of 7 days of exercise training on insulin sensitivity and responsiveness in type 2 diabetes mellitus. Am J Physiol Endocrinol Metab 2009;297:E151E156.

18 Kraniou GN, Cameron-Smith D, Hargreaves M: Effect of short-term training on Glut-4 mRNA and protein expression in human skeletal muscle. Exp Physiol 2004;89:559563.

19 Thomas DE, Brotherhood JR, Brand JC: Carbohydrate feeding before exercise: effect of glycemic index. Int J Sports Med 1991;12: 180-186.

20 DeMarco HM, Sucher KP, Cisar CJ, Butterfield GE: Pre-exercise carbohydrate meals: application of glycemic index. Med Sci Sports Exerc 1999;31:164-170. 
-21 Kirwan JP, O’Gorman D, Evans WJ: A moderate glycemic meal before endurance exercise can enhance performance. J Appl Physiol 1998;84:53-59.

-22 Kirwan JP, Cyr-Campbell D, Campbell WW, Scheiber J, Evans WJ: Effects of moderate and high glycemic index meals on metabolism and exercise performance. Metabolism 2001;50:849-855

-23 Burke LM, Collier GR, Hargreaves M: Glycemic index - a new tool in sport nutrition? Int J Sport Nutr 1998;8:401-415

24 DeFronzo RA, Tobin JD, Andres R: Glucose clamp technique: a method for quantifying insulin secretion and resistance. Am J Physiol 1979;237:E214-E223.

-25 Avram AM, Patel V, Taylor HC, Kirwan JP, Kalhan S: Euglycemic clamp study in clozapine-induced diabetic ketoacidosis. Ann Pharmacother 2001;35:1381-1387.

-26 Foster-Powell K, Holt SH, Brand-Miller JC: International table of glycemic index and glycemic load values: 2002. Am J Clin Nutr 2002;76:5-56.

$\checkmark 27$ Bertoni AG, Krop JS, Anderson GF, Brancati FL: Diabetes-related morbidity and mortality in a national sample of US elders. Diabetes Care 2002;25:471-475.

-28 Burns N, Finucane FM, Hatunic M, Gilman M, Murphy M, Gasparro D, Mari A, Gastaldelli A, Nolan JJ: Early-onset type 2 diabetes in obese white subjects is characterised by a marked defect in beta cell insulin secretion, severe insulin resistance and a lack of response to aerobic exercise training. Diabetologia 2007;50:1500-1508.

-29 DiPietro L, Dziura J, Yeckel CW, Neufer PD: Exercise and improved insulin sensitivity in older women: Evidence of the enduring benefits of higher intensity training. J Appl Physiol 2006;100:142-149.
30 Joseph LJ, Trappe TA, Farrell PA, Campbell WW, Yarasheski KE, Lambert CP, Evans WJ: Short-term moderate weight loss and resistance training do not affect insulin-stimulated glucose disposal in postmenopausal women. Diabetes Care 2001;24:1863-1869.

31 Fritz T, Kramer DK, Karlsson HK, Galuska D, Engfeldt P, Zierath JR, Krook A: Low-intensity exercise increases skeletal muscle protein expression of PPAR $\delta$ and UCP3 in type 2 diabetic patients. Diabetes Metab Res Rev 2006;22:492-498.

32 Teran-Garcia M, Rankinen T, Koza RA, Rao DC, Bouchard C: Endurance training-induced changes in insulin sensitivity and gene expression. Am J Physiol Endocrinol Metab 2005;288:E1168-E1178.

33 Poppitt SD, Keogh GF, Prentice AM, Williams DEM, Sonnemans HMW, Valk EEJ, Robinson E, Wareham NJ: Long-term effects of ad libitum low-fat, high-carbohydrate diets on body weight and serum lipids in overweight subjects with metabolic syndrome. Am J Clin Nutr 2002;75:11-20.

34 American Diabetes Association: Evidencebased nutrition principles and recommendations for the treatment and prevention of diabetes and related complications. Diabetes Care 2002;25:202-212.

35 Hughes VA, Fiatarone MA, Fielding RA, Ferrara CM, Elahi D, Evans WJ: Long-term effects of a high-carbohydrate diet and exercise on insulin action in older subjects with impaired glucose tolerance. Am J Clin Nutr 1995;62:426-433.

36 Ludwig DS: The glycemic index: physiological mechanisms relating to obesity, diabetes and cardiovascular disease. JAMA 2002;287: 2414-2423.

37 Heilbronn LK, Noakes M, Clinfton PM: The effect of high- and low-glycemic index energy restricted diets on plasma lipid and glucose profiles in type 2 diabetic subjects with varying glycemic control. J Am Coll Nutr 2002;21:120-127.

-38 Bouche C, Rizkalla SW, Luo J, Vidal H, Veronese A, Pacher N, Fouquet C, Lang V, Slama G: Five-week, low-glycemic index diet decreases total fat mass and improves plasma lipid profile in moderately overweight nondiabetic men. Diabetes Care 2002;25:822828.
39 Barkoukis H, Fiedler KM, Lerner E: A combined high-fiber, low-glycemic index diet normalizes glucose tolerance and reduces hyperglycemia and hyperinsulinemia in adults with hepatic cirrhosis. J Am Diet Assoc 2002;102:1503-1507.

40 Salmeron J, Manson JE, Stampfer MJ, Colditz GA, Wing AL, Willett WC: Dietary fiber, glycemic load, and risk of non-insulin-dependent diabetes mellitus in women. JAMA 1997;277:472-477.

41 Salmerón J, Ascherio A, Rimm EB, Colditz GA, Spiegelman D, Jenkins DJ, Stampfer MJ, Wing AL, Willett WC: Dietary fiber, glycemic load, and risk of NIDDM in men. Diabetes Care 1997;20:545-550.

42 Thomas DE, Elliott EJ, Baur L: Low glycaemic index or low glycaemic load diets for overweight and obesity. Cochrane Database Syst Rev 2007;CD005105.

43 Petersen AM, Pedersen BK: The anti-inflammatory effect of exercise. J Appl Physiol 2005;98:1154-1162.

44 Levitan EB, Cook NR, Stampfer MJ, Ridker PM, Rexrode KM, Buring JE, Manson JE, Liu $\mathrm{S}$ : Dietary glycemic index, dietary glycemic load, blood lipids, and C-reactive protein. Metabolism 2008;57:437-443.

45 Kallio P, Kolehmainen M, Laaksonen DE, Pulkkinen L, Atalay M, Mykkanen $\mathrm{H}$, Uusitupa M, Poutanen K, Niskanen L: Inflammation markers are modulated by responses to diets differing in postprandial insulin responses in individuals with the metabolic syndrome. Am J Clin Nutr 2008; 87:1497-1503.

46 Pittas AG, Roberts SB, Das SK, Gilhooly CH, Saltzman E, Golden J, Stark PC, Greenberg AS: The effects of the dietary glycemic load on type 2 diabetes risk factors during weight loss. Obesity (Silver Spring) 2006;14:22002209 . 